\title{
perifèria
}

Número 4, Julio 2006

www.periferia.name

\section{En los escenarios del tiempo. Organización sociocultural de la procreación e identidad en Oslo}

\author{
Irina Casado i Aijón - GETP / GRAFO - UAB ${ }^{1}$
}

\begin{abstract}
Resumen
Expresiones como "planear el tiempo" o "usar el tiempo" forman parte de los discursos cotidianos de los noruegos. El "tiempo" es, para los noruegos, una noción cultural básica a partir de la cual definen y explican el grado de importancia de ciertas relaciones: con ellos mismos, familiares o sociales. Este artículo tiene como principal objetivo el análisis de cómo, el tiempo es usado para buscar el equilibrio entre esas relaciones y cómo, en tanto noción cultural, también la usan para representar la maternidad y la paternidad, para conceptualizar familie y slekt y para organizar el cuidado de sus hij@s. Pero el tiempo necesita unos escenarios donde transcurrir. Así, este articulo, también pretende el análisis de la relación que se establece entre la conceptualización de familia y parientes, el individualismo y esos escenarios donde las relaciones se ponen de manifiesto. Los escenarios escogidos y las actividades que se llevan a cabo están fuertemente ritualizadas en la sociedad noruega: forman parte de su identidad nacional colectiva. Se analiza, pues, el fuerte vínculo existente entre parentesco e identidad en la medida en que, no solo el parentesco es parte del contenido identitario noruego, sino que es el vehículo a través del cual la transmisión indentitaria, sobre todo a I@s niñ@s, se produce.
\end{abstract}

\begin{abstract}
Expressions like "planning time" or "how to use time" are part of the daily Norwegian speech. For Norwegians, "time" is a basic cultural notion which is a starting point from which they explain and define the level of importance of certain relationships: with themselves, with relatives or any other social relationships. This paper seeks to analyze how time is used by Oslo inhabitants in their search for balance between, individual, family or social circles. The amount of time that Norwegians invest in themselves, also takes part in how they represent motherhood and fatherhood, how they conceptualize the familie and slekt or arrange the childcare. However, Time needs some scenarios to develop. Thus, this paper aims at the analysis of the relationship established between the conceptualization of family and relatives, individualism and the stages where these relationships emerge in order to reinforce its cohesion. Place selection and activities to undertake are strongly ritualized in Norwegian society as a part of their collective national identity. The strong relationship between kinship and identity is also analyzed since kinship is as much crucial item in Norwegian identity as it serves as the vehicle through which identity transmission, especially to children, operates.
\end{abstract}

El tiempo es una manera inseparable de las cosas: su duración.

R. Descartes

\footnotetext{
1 Agradezco a Aurora González Echevarría las correcciones y sugerencias al texto y a Jordi Grau las correcciones del abstract. Enviar correspondencia a: irinacasado@hotmail.com.
} 


\section{perifèria}

Número 4, Julio 2006

www.periferia.name

\section{Introducción}

En el seno de las instituciones noruegas, se utiliza la expresión "Sociedad amiga de los niñ@s y de las mujeres" ${ }^{2}$ debido a aquellas políticas sociales vinculadas, especialmente, a la familia y a I@s niñ@s que se aprueban y se ponen en vigor. Es una frase descriptiva formal, no se usa en la calle aunque en Noruega todos reconocen que el Estado, ya desde mediados del siglo XIX, tiene como uno de los objetivos principales hacer legislaciones destinadas a asegurar el bienestar de las mujeres, más en su faceta de madres, y el de I@s niñ@s. Después de la II Guerra Mundial, la situación política de postocupación nazi permitió a las instituciones noruegas empezar la construcción de un Estado y de una sociedad prácticamente desde cero. Se retomaron las ideas políticas de bienestar que se habían iniciado en el siglo XIX pero su aplicación tomó como base dos nuevas tendencias: por un lado, la búsqueda cada vez más acusada de la igualdad entre todos los miembros de la sociedad, y por el otro, esta situación de tabula rasa que permitió la creación de un nuevo país, puso al descubierto la necesidad de definir qué era la sociedad -y, por consiguiente, los ciudadanos- pero también qué era e iba a ser el Estado noruego, y cómo ambos se iban a relacionar.

El nuevo país se construyó teniendo como fundamentos lo que los noruegos llaman un "contrato social" entre la sociedad y el nuevo Estado. Por este contrato, todos los ciudadanos noruegos pasan a ser responsabilidad estatal. Es el Estado quien tiene que garantizar la capacidad de desarrollo personal, el acceso a todos los recursos así como la comodidad, la seguridad y la tranquilidad de cada uno de sus ciudadanos. El contrapunto, la parte del contrato que corresponde a la sociedad noruega, fue la aceptación de su participación en el desarrollo del país, del Estado y del conjunto de la sociedad a través del pago de unos impuestos elevados y la permisividad de la intervención estatal en sus vidas más cotidianas.

\footnotetext{
${ }^{2}$ La expresión noruega es Kvinne -og barnevennlig Samfunn.
} 


\section{perifèria}

Número 4, Julio 2006

www.periferia.name

Este "contrato" entre Estado y sociedad noruega ha tenido dos lecturas en el resto de países, sobre todo occidentales, que han venido de la mano de académicos pero también de legisladores. Por un lado, esta intervención estatal en la sociedad le ha valido el calificativo de "paternalista" al Estado noruego en la medida en que esa responsabilidad del bienestar de las personas lleva a que sea esta institución la que deba solucionar cualquier problema de los ciudadanos a su cargo, asimilando al viejo papel y rol que había tomado el padre en el seno de las familias, ésta obligación de garantizar la cobertura de, al menos, las necesidades más básicas y el buen desarrollo personal de cada uno de los ciudadanos. Por otro lado, este tipo de políticas ha contribuido a que el Estado noruego -junto con el resto de Estados nórdicos-, hayan sido tomados como modelo de Estados del bienestar y, en consecuencia, también las sociedades representan un modelo. Esto ha llevado a la creación de una asociación de ideas por la cual, cuánto más bienestar garantice un Estado, más alto será el nivel de desarrollo socio-institucional. Por lo tanto, las sociedades nórdicas se han considerado las socialmente más desarrolladas del mundo. Idea que se recoge en lo que los demógrafos han llamado Teoría de los modelos demográficos en la que Europa queda dividida en una parte septentrional socialmente más avanzada y una parte meridional, más atrasada y que sigue, con cierta distancia, a las sociedades del norte. Esta teoría de los modelos demográficos lo que establece es un proceso evolutivo por el cual han de pasar todos los países desarrollados. En Europa, el "punto de partida" serían las sociedades meridionales y el de llegada las sociedades del bienestar nórdicas ${ }^{3}$; la tendencia evolutiva es llegar a los modelos marcados por las sociedades septentrionales.

La investigación que inicié en Septiembre de 2001 partió de esta teoría, que recoge como particularidad el caso de Catalunya: si bien forma parte de la Europa meridional, Catalunya se desmarca de las características de esta mitad y se sitúa en un medio camino, en una tendencia más avanzada y cercana a las características septentrionales. El diseño de mi investigación ${ }^{4}$ se basó en un análisis

\footnotetext{
${ }^{3}$ Ver al respecto Domingo, A. y Miret, P. (1996). "Un dubtós retorn: Evolució recent de la família a Catalunya" en Dossier 'I... què fa la família? Societat, cultura i família a Catalunya'. Revista d'Etnologia de Catalunya, núm. 8. Pp. 54-61.

${ }^{4}$ Investigación que dio lugar a la tesis de master titulada Representacions de la maternitat i la paternitat i conceptualització dels infants i la seva cura a Oslo i Sabadell. Exercici i anàlisis crítica d'una comparació transcultural, dirigida por la Dra. Aurora González Echevarría. Universitat Autònoma de Barcelona, Diciembre 2003.
} 


\section{perifèria}

Número 4, Julio 2006

www.periferia.name

comparativo transcultural en el que se tomó Catalunya como ejemplo meridional, que se desmarca y tiende hacia el septentrional, y Noruega como ejemplo de esa sociedad del bienestar del norte de Europa. Si bien continúo llevando a cabo la investigación, en el año 2004 y una vez defendida la tesis de master, hice un cambio en su diseño a la luz de los datos etnográficos y las conclusiones a las que llegué después de esa primera etapa. En este sentido, desde Enero de 2004 mi investigación se centra en el caso noruego. Enuncio brevemente esos datos y esas conclusiones que impulsaron el cambio del diseño para la tesis de doctorado.

Si uno de los puntos de partida teóricos de la tesis de master residió en la teoría de los modelos demográficos, los objetivos de la investigación fueron el análisis de las representaciones de la maternidad y la paternidad -retomando el viejo término del siglo XIX representaciones tal como propone A. González en el capítulo 3 de su libro (2000)-, establecer un modelo de emparejamiento y/o reproducción y analizar la conceptualización de I@s niñ@s y la organización de su cuidado en ambas sociedades de estudio. Estos objetivos surgían de los dos puntos de partida teóricos principales: por un lado, como ya he dicho, la teoría de los modelos demográficos que basa su argumentación para hacer la división de las dos Europas en las características de los Estados, en las políticas y en las legislaciones que aplican y en el supuesto valorativo de cuáles son las condiciones respecto a dar respuesta a las necesidades básicas y al acceso a los recursos en las que se encuentran las sociedades que forman parte de ambas mitades. Y si, como hemos visto antes, uno de los indicativos del supuesto bienestar o desarrollo de una sociedad, es la situación de las mujeres y I@s niñ@s, la relación de ambos con las políticas de ayuda familiar y la posibilidad de hacer fácil la compatibilidad del desarrollo personal y/o profesional con la formación de una familia, se hizo necesario, pues, focalizar la investigación en temas de políticas familiares, ayudas y recursos estatales a familias, madres y niñ@s a la vez que se llevó a cabo un estudio sobre el marco cultural en donde estas legislaciones no solo surgen sino que toman sentido. Por otro lado, y respondiendo a un interés personal, el segundo de los puntos teóricos iniciales fue la Antropología de la Procreación propuesta por A. González ${ }^{5}$ que intenta dar una respuesta en el marco de las críticas que, desde los

\footnotetext{
${ }^{5}$ La propuesta fue publicada inicialmente en GONZALEZ ECHEVARRÍA, A. "Hacia una Antropología de la Procreación" en Familia y Sociedad, núm. 3 (1995) Pp. 95-110. Recientemente ha sido ohistn do
} 


\section{perifèria}

Número 4, Julio 2006

www.periferia.name

años 60, se han hecho a la Antropología clásica del Parentesco. La Antropología de la Procreación fundamenta su dominio teórico en aquello que los seres humanos no dejan al azar: la reproducción, que siempre organizan socioculturalmente. Mi interés se centró en el análisis de qué es ser madre y padre en ambos países, cómo se representan la maternidad y la paternidad, cuál era el modelo de ciclos de emparejamiento y/o reproducción y, finalmente, cómo se conceptualizan I@s niñ@s y cómo se organiza su cuidado.

Los datos etnográficos obtenidos permitieron llegar a dos grandes conclusiones: 1) Efectivamente, la teoría de los modelos demográficos basa su contenido en un modelo evolutivo por el cual todas las sociedades europeas siguen el mismo camino de "evolución" social y política cuyo final es alcanzar el estadio de desarrollo de la Europa septentrional que se considera el más avanzado y evolucionado, en este caso, del mundo. Los datos etnográficos de Catalunya y Oslo mostraron claramente que ambas sociedades no son estados diferentes de evolución de un mismo modelo evolutivo en la medida en que ambas parten de un pasado histórico, de una tradición pero especialmente de lo que llamé unas nociones culturales básicas que las hacen sustantivamente diferentes. Es en el marco histórico-cultural de cada una de las sociedades estudiadas en el que las políticas, las legislaciones pero sobre todo las representaciones de la maternidad y la paternidad, la conceptualización de I@s niñ@s y las prácticas en torno a su cuidado, tienen sentido. A la luz de esta conclusión, se hizo fundamental el estudio en profundidad de las nociones culturales básicas para poder entender y hacer comprensible la organización de la procreación y, juntamente a esto, y para completar un marco cultural donde situar los datos etnográficos, se puso de manifiesto la necesidad de un análisis histórico del nacimiento y la construcción de los Estados pero también de la construcción de las tradiciones en el que esos Estados se basan -especialmente para el caso noruego-. Hemos visto cuál es la ideología de base de la creación del Estado noruego la cual difiere de la del Estado español: las políticas y ayudas sociales de ambos países responden a esas nociones culturales, a esa tradición pero también al tipo de relación que Estado y sociedad mantienen por lo tanto dónde en Noruega el Estado adquiere la responsabilidad de madres, padres y niñ@s y su cuidado, en

revisión en GONZÁLEZ ECHEVARRÍA, A. "Informe sobre el estado del desarrollo de la Antropología de la Procreación" en Perifèria, núm. 3 (Diciembre 2005). 


\section{perifèria}

Número 4, Julio 2006

www.periferia.name

Catalunya buena parte de esa responsabilidad recae en la propia familia. Lo que ambos países tienen claramente en común es que el cuidado de los niños no es una tarea individual como tampoco lo es la reproducción: existen diferentes formas de dependencia-soporte, en un caso estatal, en otro familiar. Y 2) La segunda conclusión a la que llegué fue que las nociones culturales básicas están en el origen y determinan la organización de la procreación de las dos sociedades: es a través de esas nociones específicas y diferentes para cada una de las sociedades, que se deben entender las prácticas, las representaciones y las conceptualizaciones procreativas pero también las del resto de la sociedad. Así, la organización de la procreación en Oslo está vinculada a varias nociones culturales como el individualismo, el tiempo, la igualdad o la libertad mientras que en Catalunya tienen especial importancia nociones como familia, responsabilidad o dedicación. Por lo tanto, las lógicas culturales subyacentes influyen y/o determinan la organización de la procreación y por este motivo esta, y en especial el cuidado de I@s niñ@s, se debe entender como una estrategia estrechamente vinculada al entorno sociocultural. Junto a estas dos conclusiones principales, también se abrieron líneas nuevas de investigación de las cuales la conceptualización de la "sangre" en las relaciones familiares y de parentesco así como la relación entre parentesco e identidad requerían una especial atención en una segunda fase de la investigación.

De esta manera, ante la necesidad de profundizar en el conocimiento de los contextos socio-culturales e históricos, del análisis de las nociones culturales básicas implicadas en la organización de la procreación previamente al análisis de la procreación y juntamente a la fascinación de los datos etnográficos obtenidos en Oslo y un interés personal por estos, me llevó a diseñar una investigación para la tesis doctoral en la que solo el caso noruego fuera objeto de estudio. Así, en Enero de 2004 empecé la segunda fase del trabajo de campo en Oslo con tres hipótesis de trabajo de partida surgidas de los datos noruegos:

a) El "tiempo" como noción cultural está en la base de la conceptualización de las relaciones familiares, de parentesco y del resto de relaciones sociales. Es a través del "tiempo" que las personas que viven en Oslo identifican el grado de importancia de sus relaciones. 


\section{perifèria}

Número 4, Julio 2006

www.periferia.name

b) En un contexto en el que la concepción del "yo" y del individualismo tiene gran importancia y por lo tanto se le debe dedicar "tiempo", las actividades que la kjernefamilie ${ }^{6} \mathrm{O}$ la familie realizan con el objetivo de cohesionar la relación entre sus miembros siempre son aquellas que se denominan Typisk norsk, es decir, típicamente noruegas. De esta manera, es mediante las relaciones familiares y de parentesco que se usan no solo unos escenarios sino que se realizan unas actividades que forman parte del contenido de la identidad nacional noruega. Se transmite así, de forma generacional, lo que es ser un godt normann, un buen noruego.

c) Consecuentemente, la organización de la procreación y las relaciones familiares y de parentesco son un elemento identitario noruego considerado específico.

Con estas hipótesis iniciales, mis objetivos fueron varios: 1) ampliar y profundizar en el análisis de las nociones culturales básicas que mayor implicación tienen en la organización de la procreación y analizar la creación del Estado noruego y sus políticas públicas en torno a la familia, a la maternidad y la paternidad, I@s niñ@s y su cuidado pero también estudiar cuál fue el proceso de creación de la identidad noruega; 2) mi interés por la conceptualización de la "sangre" como base a partir de la cual se identifican a los familiares o los parientes - pero no la única ya que, como he mencionado antes, el "tiempo" es otro elemento igual de determinanteme llevó a la necesidad de definir e identificar qué entienden los noruegos por familie y qué entienden por slekt ${ }^{7}$, a qué personas incluyen en cada una de estas dos categorías, por qué y qué criterios de diferenciación usan. Una vez hecho esto, se analizarían las diferentes tipologías de familias que hay en Oslo y qué procesos se usan para incluir a personas sin vínculo consanguíneo ni de afinidad en la familie; 3) Un tercer objetivo correspondería a la corroboración de los datos y del análisis que se hizo para la tesis de master respecto a las representaciones de la maternidad y la paternidad y la ampliación de este tema de estudio al hilo de las hipótesis de trabajo formuladas. Así, qué es ser madre o qué es ser padre en la sociedad noruega, qué sentimientos genera, las anticipaciones, cuáles son las

\footnotetext{
${ }^{6}$ Literalmente "núcleo familiar".

${ }^{7}$ Concepto noruego que hace referencia a una relación entre personas que llevan el mismo apellido no por matrimonio sino porqué descienden de un antepasado común.
} 


\section{perifèria}

Número 4, Julio 2006

www.periferia.name

prácticas o el ciclo de emparejamiento y/o reproducción son analizados desde la óptica del "uso del tiempo" como noción cultural y del vinculo entre kjernefamilie e identidad noruega; 4) Análisis de la conceptualización de I@s niñ@s y organización socio-cultural de su cuidado. A pesar de que este tema fue tratado en la primera fase de la investigación, ha sido especialmente relevante profundizar en él teniendo en cuenta la importancia o incluso centralidad que tienen los niñ@s en la sociedad noruega y cómo una parte del contenido identitario se construye a su alrededor. Se desarrolló en este sentido una línea de investigación abierta en el trabajo de campo del 2002 que fue entender la organización del cuidado como una estrategia adaptativa al contexto político y a los recursos públicos pero también en buena manera determinada por las nociones culturales básicas subyacentes; y 5) el tema Parentesco e identidad surgió como línea abierta de investigación pero ha sido central en esta segunda fase de la investigación. La fuerte relación que se establece entre parentesco e identidad nacional pero también local se ha traducido en dos de las hipótesis de trabajo que han guiado la investigación ya que, junto con el contexto cultural, es indispensable el análisis de ese vínculo para entender la organización de la procreación en Oslo.

En este artículo me propongo abordar de manera breve los objetivos y los temas analizados en profundidad en mi tesis de doctorado. La organización de la procreación en Oslo -y por extensión en toda Noruega- tiene unos escenarios dónde se pone de manifiesto, dónde se desarrolla. Unos escenarios y unas prácticas que están fuertemente ritualizados en la medida en que forman parte de la identidad nacional noruega. Así, el tiempo entendido como noción cultural que está en la base de la organización de las relaciones sociales pero también con uno mismo tiene unos escenarios determinados donde transcurre y en el que se realizan unas actividades ritualizadas, y es en cada uno de esos escenarios en los que se cohesionan también determinado tipo de relaciones. Así, en un contexto en el que el individualismo tiene una gran importancia y es por eso que se dedica una parte importante del tiempo diario a uno mismo, el tiempo y las actividades que se realizan entre los miembros de la kjernefamilie -entiéndase, familias nucleares, familias monoparentales o familias reconstituídas-, tienden a distribuirse durante 


\section{perifèria}

Número 4, Julio 2006

www.periferia.name

los fines de semana. Es en ese momento en que se busca el espacio y el tiempo para cohesionar las relaciones familiares consideradas más importantes: ese espacio corresponde a unos escenarios considerados típicos noruegos donde se realizan unas actividades consideradas por los propios noruegos como identitarias. El objetivo, pues, de este artículo es analizar no solo la relación entre tiempo, prácticas y escenarios vinculada a la organización de la procreación sino hacer entendible esa relación enmarcándola en el contexto cultural del que surge pero también en un contexto de políticas estatales que garantizan ciertos recursos públicos además de ser el Estado uno de los principales actores en la creación de esa identidad noruega que se basa en una tradición inventada.

\section{Nociones culturales básicas y el Estado del bienestar noruego}

La posibilidad de poder llevar a cabo el análisis comparativo transcultural en el estudio de las sociedades permite, entre muchas otras cosas, poder poner de manifiesto la diversidad de soluciones, prácticas, estrategias o representaciones que diferentes sociedades humanas utilizan ante un mismo fenómeno. Cada una de las soluciones que las sociedades ponen en práctica, cada una de las creencias o las representaciones que intentan dar respuesta a preguntas similares pero también aquellos modos de hacer y de pensar específicos de cada una de las sociedades son los rasgos que confieren su singularidad cultural. Inicialmente, poder analizar comparativamente cómo en Sabadell y Oslo representaban la maternidad y la paternidad y cómo organizaban la procreación hizo emerger aquellos aspectos que ambas sociedades europeas, occidentales, compartían pero especialmente fue muy útil para poner de relieve aquellos que eran divergentes. La pregunta siguiente fue ¿por qué en dos sociedades occidentales europeas existen diferencias importantes en cómo madres y padres se representan y en cómo I@s niñ@s se conceptualizan, se cuidan y se educan? El siguiente paso, una vez identificadas especialmente las diferencias, fue buscar su causalidad concretamente, por la elección de la perspectiva de análisis, en el caso de Oslo.

A mi entender, dos son las causas principales de que la organización de la procreación en Oslo sea cultural y socialmente específica: la lógica cultural 


\section{perifèria}

Número 4, Julio 2006

www.periferia.name

subyacente y el marco político y económico impulsado por el Estado noruego ${ }^{8}$. En realidad, se trata de un solo contexto en el que ambas causas no solo interaccionan y comparten los mismos elementos sino que se entienden una en función de la otra. Veamos cómo se construye y funciona este contexto.

\section{Las nociones culturales básicas}

Ante el análisis de cualquier fenómeno social es imprescindible situarlo en el marco cultural del que surge, se desarrolla y, consecuentemente, tendrá sentido. Entendiendo marco cultural como todos los elementos que intervienen en el hecho de que una sociedad tenga una forma específica de funcionar y organizarse pero también de entenderse y explicarse a sí misma y a los demás, pueden identificarse unas ideas que en cierta manera constituyen el sustrato de ese marco cultural y que, efectivamente, es a partir de las cuales ese marco se construye y posteriormente la sociedad busca soluciones o estrategias a las situaciones o a los fenómenos comunes a todas ellas. Llamo a esas ideas de base nociones culturales básicas. Estas nociones son cambiantes en el tiempo, cada época tiene las suyas, y a la vez puede ir cambiando su conceptualización aunque de manera imperceptible en un corto o medio plazo de tiempo. Es posible que alguna noción sea compartida entre diferentes sociedades incluso puede que también se comparta su representación, pero es la combinación de esas nociones lo que hace posible que el contexto cultural se fundamente. Otra posibilidad es que sociedades con nociones culturales básicas diferentes lleguen a las mismas soluciones o a las mismas estrategias, entonces es posible que lo que se comparta sea la representación de alguna de ellas. Es en este sentido que la comparación transcultural es fundamental para la construcción del conocimiento antropológico.

En la sociedad noruega existen unas nociones culturales básicas que inciden en su funcionamiento y organización pero especialmente en cómo sociedad y individuos se representan y se entienden a sí mismas. Esas nociones principales son: el individualismo y la igualdad. Partiendo de estas nociones, el contexto cultural

\footnotetext{
8 Más allá del caso noruego, haría una propuesta que podría utilizarse para el análisis de otras sociedades: para entender los fenómenos y sus lógicas es necesario, previamente, localizar primero y analizar después las nociones culturales básicas de esa sociedad en la medida en que es a partir de la inserción de esas nociones en el funcionamiento y organización de una sociedad a partir de la cual podemos entender y hacer comprensibles los fenómenos que estamos estudiando. $Y$, para el fenómeno concreto de la organización de la procreación, creo también necesario el estudio de las formas de dependencia en la medida en que la reproducción no es individual como tampoco lo es la vida.
} 


\section{perifèria}

Número 4, Julio 2006

www.periferia.name

noruego también está formado por ideologías muy vinculadas como por ejemplo: el sentido de justicia y la necesidad de consenso, analizadas por A. Archetti (1991) o las de paz y tranquilidad, estudiadas por M. Gullestad (1992, cap. IV), entre otras. Así, para la sociedad noruega estas nociones pueden entenderse del siguiente modo:

- Individualismo. La noción de individuo es fundamental en Noruega. Se entiende como independencia y autonomía de cada una de las personas respecto al conjunto de la sociedad, incluidas aquellas personas consideradas más cercanas. Los noruegos tienden a separar, aunque de forma poco clara como veremos, su yo individual del resto de la sociedad y lo conceptualizan como una relación más en el conjunto de las relaciones sociales. Al ser así, es imprescindible que esa relación que tienen consigo mismos se mantenga activa y se refuerce diariamente porque solo así podrán mantener activas el resto de relaciones; solo si la relación con su yo individual es positiva y fluida podrán serlo el resto de relaciones. En este sentido una informante decía al respecto de la vida en pareja: "Bueno, claro que salen separados, ¿cómo van a hacerlo juntos? Hacerlo siempre todo juntos no es bueno. Además, claro, a los dos no les gusta lo mismo. ¿Cómo vas a hacer algo que no te gusta? Luego la relación no iría bien. Siempre tienes que hacer lo que quieres. Aquí en Noruega no se entiende que la gente no haga lo que quiere. Si haces lo que quieres y lo que te gusta, vas a estar bien contigo, te vas a sentir contento y bien y así puedes estar bien con los demás, con tu pareja y tus hijos. Si no haces lo que quieres, luego no puedes estar bien con los demás". Entendiendo pues, el individualismo como relación con el yo pero también como independencia y autonomía ${ }^{9}$, en la práctica esta noción se vislumbra en la dedicación de una parte del tiempo diario o bien a estar con el yo individual pero especialmente a poder decidir qué se quiere hacer, cómo y cuándo.

- Igualdad. La noción de igualdad está en la base de toda la organización social pero también de las políticas estatales en Noruega. Por igualdad debe entenderse la semejanza entre todas las personas: así, el Estado se basa no solo en que todos los ciudadanos están bajo su responsabilidad sino que sus políticas, ya desde el final de la II Guerra Mundial, son de carácter universal. Ante el Estado, todos los noruegos

\footnotetext{
${ }^{9}$ Ver Gullestad, M. (1992).
} 


\section{perifèria}

Número 4, Julio 2006

www.periferia.name

tienen los mismos derechos pero también los mismos deberes, sin distinción. Pero la noción de igualdad también es fácilmente observable en la vida cotidiana de las personas: se trata pues de homogenizar la sociedad, de hacer ciudadanos parecidos, sin que uno sobresalga del resto ni por defecto ni por exceso -para este cometido, por ejemplo, en los colegios no hay calificaciones hasta que no se llega a la secundaria. De esta manera, impiden la competencia entre los alumnos pero también que cualquiera de ellos pueda sentirse mal por estar detrás del resto-. Así, a pesar de que paseando por las calles de Oslo pueden encontrarse personas vestidas siguiendo determinadas estéticas, en general las personas visten siguiendo los mismos modelos tratando de no hacer visible, entre otras cosas, su nivel económico. Esta igualdad también se aplica a las relaciones de género por las que el Estado noruego apuesta de forma decisiva especialmente en sus políticas familiares y de la infancia a veces en detrimento de la dinámica social -me refiero, concretamente, al hecho de que a pesar de que, desde 1978 cuando se implantó la Fødselspermisjon o baja por nacimiento, los padres tenían derecho a disfrutar de este permiso, en 1993 el Estado aprobó la fedrekvoter o la reserva de 4 semanas de ese permiso para exclusivamente los padres con la intención de fomentar la participación paterna-. Pero también es una noción interiorizada y defendida por el conjunto de la sociedad. En resumen, los noruegos son más iguales cuanto más parecidos son entre ellos.

Junto a estas dos nociones culturales básicas principales en la sociedad noruega, existen otras que de igual manera conforman el contexto cultural. Estas son: 1)

Sociedad. Como ya he mencionado anteriormente, la noción de sociedad necesita ser definida especialmente después de la II Guerra Mundial, momento de elaboración del "contrato social". A pesar de este momento en que lo que suponía era más una conceptualización formal con repercusión legislativa, la conciencia de sociedad empieza a formularse con las revoluciones europeas de $1848 \mathrm{y}$, posteriormente en 1905, cuando Noruega se independiza de Suecia. La sociedad noruega tiene una fuerte consciencia colectiva: todos forman parte de la sociedad $y$, en tanto que iguales, ocupan todos un mismo lugar. Así, en la práctica, esta consciencia de sociedad se aprecia por ejemplo en la organización de trabajos comunitarios (dugnad) -como arreglar las calles- o en el sentido del deber social por el cual pagan altos impuestos sabiendo que, efectivamente, tendrá una 


\section{perifèria}

Número 4, Julio 2006

www.periferia.name

repercusión beneficiosa para todos. A su vez, esta consciencia de pertenecer a una sociedad implica también poco margen para el desarrollo de, a pesar del individualismo y la libertad, la libertad personal. Hay unos límites sociales muy marcados que se deben respetar así es como, el ejercicio de la libertad sobrepasándolos, puede llevar a la marginación social de la persona. Estos límites son sobre guardados por los propios miembros de la sociedad cada uno de los cuales puede, y a veces se siente con el deber, de recordarlos a aquellos que los transgreden. Vemos, pues, como en cierta manera la noción de individuo y la de sociedad entran en contradicción; 2) el Tiempo. Organizar o planear el tiempo es una cuestión fundamental en la vida diaria de los noruegos. Es importante para los noruegos sentir que en todo momento "hacen lo que deben hacer" y que aprovechan bien el tiempo. La expresión noruega más utilizada es "usar bien el tiempo" (bruke tiden riktig) vinculada, generalmente, al sentido del deber -en este sentido, una de mis informantes me decía cuándo podía o no descansar en el sofá según si aquel día había trabajado mucho o no- ${ }^{10}$. Como veremos, el tiempo también es usado para distinguir entre las redes de relaciones familiares, de parientes y sociales, qué personas se consideran más cercanas y cuáles más lejanas; 3) el Trabajo. Relacionado con la noción de individualismo, el trabajo es considerado fundamental para el desarrollo personal pero también como necesario para poder optar al tiempo de descanso o de actividades de ocio. No solo se entiende por trabajo el remunerado sino cualquier tipo de actividad que no implique ocio.

En el intento de buscar el origen cultural de las nociones de individualismo o trabajo, es probable que podamos situarlas en la Reforma religiosa del siglo XVI: Noruega se convirtió en Luterana, doctrina que justamente propugna como directriz que el ser humano debe ser autónomo y autosuficiente (individualismo) y una de las vías para conseguirlo es a través de su trabajo. Otra noción que podría tener su punto de referencia en el luteranismo es la de sociedad ya que, aunque surgida en la posguerra, su relación con el individualismo se podría asociar a la idea luterana de que la moral individual debe estar de acuerdo con la moral pública o del conjunto de la sociedad.

${ }^{10}$ Cabe destacar que el mismo idioma noruego utiliza verbos de obligación en estas construcciones gramaticales como "deber" o "tener que". 


\section{perifèria}

Número 4, Julio 2006

www.periferia.name

He presentado, pues, algunas de las nociones culturales fundamentales en la sociedad noruega. Con mayor o menor incidencia, todas ellas tienen una implicación determinante en cómo las personas que viven en Oslo organizan su procreación o cómo representan la maternidad y la paternidad, como veremos. Pero como ya he anunciado, hay otro elemento que interviene en esa organización convirtiéndose en una de sus causas: el Estado de bienestar noruego, en su función de institución pública que tiene la responsabilidad de todos los ciudadanos, que legisla y que interviene en la vida cotidiana y privada de las personas y que, por lo tanto es impulsor y garante de un marco político y económico en el que se debe entender la organización de la procreación. La representación del Estado y su función se ha construido a partir de esas nociones culturales básicas de manera que no solo comparten unos referentes culturales comunes sino que el Estado los garantiza mediante sus leyes o políticas a la vez que adquiere una parte cultural en su conceptualización. Es así como, siendo dos elementos que crean el marco institucional y cultural noruego, en realidad mediante su interacción y compartiendo los mismos referentes culturales, conforman un solo contexto.

\section{El Estado de bienestar noruego}

Dicen los noruegos que parte del éxito del Estado de bienestar noruego se debe a que su creación, basada en el "contrato social" de después de la II Guerra Mundial, se llevó a cabo sin ninguna intervención externa. Dos partes, sociedad y Estado, asentaron las bases, fijaron unos objetivos comunes pero también establecieron unas condiciones, derechos y deberes mutuos, inmodificables -independientemente del partido político que gobernara- que cristalizaron en la social-democracia. La ideología de base de la social-democracia recuerda al sentido del trabajo comunitario (dugnad), es decir, el trabajo en conjunto por conveniencia de ambas partes.

El contrato social de 1945 asentó las bases para la construcción de un estado de bienestar, concretamente, con la introducción, un año más tarde, de una nueva fórmula en las políticas sociales: la universalidad. Unas políticas sociales que desde finales del siglo XIX habían estado en el núcleo de los debates políticos -de los cuales Katti Anker Møller, feminista noruega ${ }^{11}$, fue una crucial impulsora-, y que

\footnotetext{
${ }^{11}$ Ver al respecto I. Blom (1996).
} 


\section{perifèria}

Número 4, Julio 2006

www.periferia.name

habían conseguido la introducción de políticas de ayuda social y subsidios especialmente para madres e hij@s. Así, con una tradición de legislaciones y políticas favorecedoras de ciertos sectores sociales, la introducción de la universalidad en 1946, basada en la noción de igualdad, supuso no solo un primer paso hacia la materialización de ese contrato social sino también de un estado de bienestar ya que, como afirman Seip e Ibsen "el grupo beneficiario no se limitaba a una clase social concreta ni se determinaba en virtud de los ingresos ni de la cotización a un esquema de seguridad social ligado al mercado laboral. Todos lo niños y familias tenían derecho al subsidio" (1996:81-82). Analizo en este apartado el Estado de bienestar en tanto creador del marco político y económico del cual dependen los noruegos para organizar su procreación, dejando para el apartado de "parentesco e identidad" el análisis del origen del Estado vinculado a la creación de una nación y de una identidad nacional, a partir de 1905.

He apuntado anteriormente cómo, a partir de la interacción del Estado con las nociones culturales básicas se crea un contexto general que es el marco para comprender la organización de la procreación en Oslo. De hecho, el origen del Estado de bienestar noruego se encuentra en la aplicación de la noción de igualdad en las políticas sociales mediante su universalización pero también entre hombres y mujeres -igualdad de la que el Estado es especial defensor-. Una de las cláusulas de ese contrato social dictaba que todos los ciudadanos noruegos eran iguales y, por lo tanto, tenían los mismos deberes (pagar impuestos, entre otros) pero también los mismos derechos (tener igual acceso a los recursos públicos). Esa relación entre Estado y Sociedad va más allá en la medida en que el Estado es visto por las personas también como un igual. Es decir, no se trata de una relación jerárquica en la que el Estado toma una posición coactiva de superioridad sino una relación, un contrato entre iguales en la que al Estado no le hace falta tomar posturas de poder porque cumple, también, con su parte del contrato. De nuevo, las nociones de igualdad y de sociedad entran en juego por ambas partes: todos deben cumplir su parte del contrato. Así, una informante me decía: "No veo al Estado como algo que está encima mío. Los noruegos cumplimos las normas, las leyes. Vemos al Estado como un amigo y esto ha sido indispensable para que la sociedad sea como es y que las cosas hayan funcionado. No hace falta ir contra el Estado aunque tampoco hace falta aceptarlo todo si no estas de acuerdo. Las 


\section{perifèria}

Número 4, Julio 2006

www.periferia.name

personas tienen derecho a escoger". Aunque ya hemos visto como esa libertad está estrictamente limitada no solo por el Estado sino también por el resto de la sociedad, la verdad es que el Estado abre un amplio abanico de posibilidades para que las personas puedan escoger, aunque esas posibilidades estén ya establecidas $y$, sobre todo legisladas, y a pesar de que pocas veces se deje de recurrir a la ayuda estatal.

El vínculo entre Estado y nociones culturales básicas, pues, reside en el hecho de que el Estado utiliza en concreto la noción de igualdad para basar sus políticas de bienestar pero también es el principal garante de poder poner en práctica la noción de individualismo y también la de trabajo, la de tiempo o cohesionando a la Sociedad. $Y$ es especialmente visible en cómo las personas organizan la procreación pero también representan la maternidad y la paternidad.

Las políticas sociales destinadas a la familia y a I@s niñ@s junto con los subsidios económicos estatales y especialmente con los discursos institucionales que tienden a la creación de modelos de aquello que se considera correcto, permiten la creación de un espacio en el que madres y padres pueden plantearse tener hij@s sabiendo que tienen un sustento económico mediante por ejemplo la baja por nacimiento (Fødselspermisjon) -que consiste en 42 semanas cobrando el $100 \%$ del sueldo o en 52 semanas cobrando el $80 \%$. De estas semanas, 4 son obligatorias para el padre (fedrekvoter) y en el caso que las rechazara se perderían-, la pensión familiar (Barnetrygd) -soporte económico complementario al resto que se instauró en 1946 y que consiste en una mensualidad que se paga generalmente a la madre por cada hij@ hasta los 16 años-, el sistema de beneficio al contado (Kontantstøtte) por el

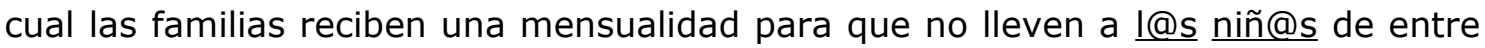
1 y 2 años a las guarderías públicas o, finalmente, las posibilidades que tienen padres y madres de reducir sus jornadas laborales para cuidar a sus hij@s -el periodo va desde un mínimo de 12 semanas a un máximo de 104 en las que padres y madres escogen el porcentaje de horas que quieren trabajar y si quieren hacer la reducción de manera simultanea o consecutiva-. Como vemos, el núcleo de estas políticas y subsidios, más que las familias, son @@ niñ@s: es por su bienestar, por tener un mejor cuidado y atención de sus principales responsables, los padres y madres. La responsabilidad del padre también esta legislada, como lo está la de la 


\section{perifèria}

Número 4, Julio 2006

www.periferia.name

madre: la ley que protege a l@s niñ@s enfatiza que la obligación parental es una preocupación independiente a aquello que las personas adultas hayan decidido sobre su relación. De esta forma, el Estado legisla y regula no solo las tipologías de familias existentes en la sociedad sino también el modelo de cuidado de $\underline{\text { @s }} \underline{\text { niñ@s }}$ así como también crea los discursos que inciden en la sociedad y que establecen qué es lo que está bien y qué es lo que no. Para A. Leira, "different forms of welfare state promote different forms of family, and the way in which motherhood, fatherhood and childhood is politically institutionalized"12. Pero no solo eso. Cabe enmarcar estas regulaciones en la relación existente entre Estado y Sociedad para entender que aquello que las instituciones públicas propugnan y aluden en sus discursos sea puesto en práctica por la sociedad. Esto no quiere decir que la Sociedad haga todo lo que el Estado dice ni que la Sociedad no sea impulsora de discursos y nuevas pautas: lo esencial en esto son los canales de aceptación, comprensión y respeto igualitario entre ambos entes.

De nuevo, mediante estas legislaciones y subsidios, el Estado se convierte en garante del individualismo en la medida en que padres y madres no se sienten culpables por necesitar tiempo para sí mismos: hay otras personas que se ocupan de sus hij@s con igual cuidado, permite la igualdad de oportunidades entre padres y madres - recordemos que la igualdad, en este caso entre géneros, también es uno de los objetivos prioritarios de la legislación noruega- y por lo tanto intenta, aunque no siempre con éxito, que se combine la responsabilidad entre ellos. Permite también no solo mediante las legislaciones sino mediante la creación de una conciencia colectiva que el cuidado de l@s niñ@s sea uno de los objetivos prioritarios para el Estado pero también para la Sociedad de manera que no es infrecuente encontrar empresarios que permiten la flexibilización de los horarios laborales con finalidades familiares. Es así como el Estado facilita en tiempo y en dinero que los noruegos puedan tener hij@s y por lo tanto que, padres y madres, tengan la posibilidad de combinar con cierta tranquilidad su trabajo y el cuidado de sus hij@s.

12 Citado en Leira, A. (1996). Parents, Children and the State: Family obligations in Norway. Oslo: Institutt for samfunnsforskning y extraído de Leira, A. (1994). "Combining work and Family. Working mothers in Scandinavia and the EC" en Brown, P y Crompton, R. (eds.) (1994). A New Europe? Economic Restructuring and Social Change. Londres: UCL Press. 


\section{perifèria}

Número 4, Julio 2006

www.periferia.name

El punto central son, pues, I@s niñ@s. El Estado toma un papel intervencionista - también denominado paternalista- puesto que, al ser responsable de todos los ciudadanos, tiene la obligación de velar por su bienestar, y especialmente por el de I@s niñ@s. De este modo, el Estado legisla y, por lo tanto regula, dos aspectos esenciales relacionados con la procreación: por un lado, y como ya hemos visto, el cuidado de I@s niñ@s pero, por el otro, la tipología de uniones que se dan en la sociedad -el Estado ha ido incorporando a la legislación las nuevas formas de unión entre adultos que en la sociedad ya se estaban dando-. En este ámbito queda poco o nada sin que esté institucionalizado: el Estado, de esta manera, sin tener un control autoritario a la vez que tiene un papel aceptado socialmente, sí que interviene en aspectos tan personales como el tipo de unión entre adultos. En este sentido, el Estado noruego también es uno de los principales creadores de discursos en torno a aspectos sociales relevantes que tienen especial incidencia en las pautas que los noruegos siguen, aunque a veces existen reacciones sociales contrarias a las propuestas estatales. Parece existir, en este sentido, una contradicción entre el individualismo y la dependencia estatal aunque la lógica de la coherencia de ambas nociones reside en la relación entre Sociedad y Estado, pero sobre todo en el papel social que tiene este último: amigo, benefactor, que vela por los intereses sociales y del que los noruegos tienen una confianza fundamental para el funcionamiento del contrato social.

Lo esencial en esto son los engranajes de cohesión existentes entre las dos causas de la especificidad noruega que he analizado en este apartado: las nociones culturales básicas y el Estado de bienestar. He intentado mostrar las formas de interacción de ambos actores en tanto que, es mediante esa relación, que es posible la existencia de un solo marco contextual en el que ambas causas, además, se explican una en función de la otra. De este modo, el Estado necesita de las nociones culturales básicas noruegas para legitimar no solo su papel sino las políticas, las regulaciones o legislaciones y los discursos que crea y aplica. A la vez, las nociones culturales básicas encuentran en las políticas y los discursos institucionales el marco donde materializarse y por lo tanto una forma de seguir vigentes -pero no inmutables-. Es así como, ese contexto general representa, a la vez, el marco contextual donde se debe situar la construcción de la identidad nacional noruega que analizaré en el último apartado de este artículo. Es en este 


\section{perifèria}

Número 4, Julio 2006

www.periferia.name

marco general en el que se debe situar y entender la organización de la procreación y las representaciones de la maternidad y la paternidad en Noruega.

\section{¿Qué es familie? ¿Qué es slekt?}

La presencia estatal en la vida privada de las personas ha llevado a la regulación de la mayoría de uniones que existen en noruega. Formalmente, ante la gran diversidad de formas de unión entre adultos, en la legislación el término familie muy pocas veces hace referencia a una unidad sino que regula los derechos y deberes de los individuos que están emparentados los unos con los otros mediante lazos de descendencia, matrimonio o por otros acuerdos o contratos que tienen contenidos similares a estos. Las bases de estas legislaciones se centran en la consanguinidad o afinidad para explicar qué personas se consideran familie y también quiénes son parientes, aunque la relación con estos últimos no está en el núcleo del interés estatal en la medida en que, en principio, no repercute ni el bienestar de niñ@s ni implica la protección económica y material directa en situaciones de separación y/o divorcio.

De la misma manera en que la sociedad pone en práctica otro tipo de uniones entre adultos con finalidad de crear lazos de familiaridad que el Estado aún no ha regulado, existen conceptualizaciones que no encajan del todo en las institucionales respecto a lo que las personas que viven en Oslo entienden por familie y por slekt. La finalidad es diferente: mientras que el Estado intenta regular unos vínculos entre personas en cuyo centro hay unos bienes materiales pero sobre todo, en el debido caso, un@s niñ@s que, recordemos, son los destinatarios de buena parte de las ayudas y de las políticas sociales, las personas mediante ambos conceptos pretenden una clasificación de aquellas personas que por sangre, por matrimonio o por otras vías de incorporación forman parte de su genealogía, y por la cual establecerán los grados de obligaciones y derechos con cada una de ellas.

Mis informantes utilizan, como también lo hace el Estado, la consanguinidad y la afinidad como criterios de unión entre las personas que consideran parientes. Trazan sus árboles genealógicos -incluyendo a aquellas personas que individualmente consideran oportunas-, en función de un lazo consanguíneo principal a partir del cual incorporan a las personas afines, por matrimonio o por otro tipo de unión. La memoria genealógica, en general, no discurre más que dos 


\section{perifèria}

Número 4, Julio 2006

www.periferia.name

generaciones en ascendencia a pesar de que en algunas ocasiones se incluye también no más de dos personas de la tercera generación ascendente que coinciden con ser personas que han tenido un trato directo con el informante. A pesar de esto, hasta la segunda generación ascendente se incluyen todas las personas aunque el informante no las haya conocido nunca, a diferencia de las personas que se incluyen de la tercera generación en ascendencia. Es a partir de la pareja de más edad -los abuelos para Ego- que se trazan las líneas de consanguinidad entendiéndose a esta pareja como los antepasados comunes de todas las personas que se sitúan en algún lugar de las líneas consanguíneas. Por el criterio de afinidad, se incluye en la genealogía a las personas incorporadas por ekteskap o por samboerskap ${ }^{13}$, es decir parejas vigentes en el momento etnográfico aunque en ocasiones, dependiendo del grado de relación creado con Ego, pueden incluirse a personas de relaciones ya finalizadas.

A diferencia del Estado, ।@s informantes introducen una clasificación sobre la base de la consanguinidad y la afinidad para diferenciar entre todas las personas incluidas en las genealogías. Así, hacen tres categorías distintivas:

1.- Slekt. Las personas incluidas en esta categoría son aquellas que descienden de un antepasado común y por ese motivo llevan el mismo apellido -o deberían llevarlo ya que la cuestión del apellido en las últimas décadas ha sido objeto de cambios significativos-. Así, en principio, no son slekt las personas afines pero esto no siempre es así ya que pueden incluirse a los afines de las generaciones ascendientes pero no a los de la generación de Ego. De esta manera, Ego forma parte de dos grupos de slekt, el materno y el paterno y ambos tienen como origen al miembro de la generación ascendente mayor que se recuerda aunque se considera como origen también, por extensión, a ambos miembros de la pareja aunque solo uno de ellos sea el dador del apellido. En la práctica, Ego solo potencia uno de los slekt del que forma parte: la predilección de uno más que otro muchas veces está relacionado con aquel de los dos que posee una granja ( $g$ ård) familiar y por lo tanto está más cercano a lo que la identidad nacional considera "típico noruego". Los noruegos tienen gran interés en buscar sus antepasados y, a veces,

${ }^{13}$ Conceptos en noruego que se traducen como "matrimonio" el primero y "pareja de hecho" el segundo. 


\section{perifèria}

Número 4, Julio 2006

www.periferia.name

lo manifiestan escribiendo libros sobre sus slekt o en ocasiones como las slektstevne, que son reuniones de todas las personas que tienen el mismo apellido, generalmente organizadas por la persona considerada como origen del slekt, por lo tanto la más mayor, y que se celebran usualmente una vez durante la vida de esa persona mayor.

2.- Familie. Muchas veces, los informantes en sus discursos no usan el término slekt porque tienen una extensa categorización de personas identificadas como familie que en la cotidianidad es la que más usan. Aunque a veces los términos familie y slekt no se diferencien de forma clara, las personas que dentro de las genealogías son categorizadas como familiares son aquellas que están relacionadas con Ego por lazos consanguíneos próximos y por afinidad con esos consanguíneos. La falta de delimitación entre una categoría y otra, en mi opinión, se pone especialmente de manifiesto cuando se intentan definir ambos términos de forma teórica pero no cuando emergen en la práctica en la medida en que, es en la cotidianidad en la que interviene una de las nociones culturales antes analizadas: el tiempo. El criterio de identificación de la familie es la frecuencia de la relación. El tiempo entendido como el número de ocasiones o la frecuencia en la que se ven, define el grado de relación que existe entre las personas de las genealogías. De esta manera puede entenderse que ciertas personas del grupo slekt se consideren familie: se trata de aquellas personas identificadas como nørmesteslekt que, además de formar parte del slekt son consideradas como familie porque la relación con Ego es más estrecha y frecuente durante todo el año. Por otra parte, no todas las personas consideradas familie tienen que ser miembros del slekt porqué no todas descienden de un antepasado común. La diferenciación dentro del grupo familie es muy amplia y está basada en la regularidad en que unos y otros se visitan ${ }^{14}$, aunque el tiempo también hace referencia al hecho de, en palabras de una informante, "haber compartido una historia juntos" es decir que el tiempo compartido haya fortificado no solo la relación sino que haya proporcionado unos recuerdos que, en la práctica, unen. Lo que diferencia a la familie del slekt es que la seguridad de su existencia, de que las personas siempre van a estar ahí en caso de

14 La expresión "ir de visita", gå på besøk, es muy utilizada en Oslo. Las visitas son una forma de cohesionar las relaciones (no solo familiares o parentales) muy ritualizada. Entre la familie se entiende que la proximidad reside en la cantidad de veces que se visitan al margen de aquellas que son esenciales para mantener activas las relaciones: Navidad, verano, ceremonias o determinadas fiectac 


\section{perifèria}

Número 4, Julio 2006

www.periferia.name

necesidad corresponde a la familie, a pesar de que, en la práctica, pocas veces se recurre a la ayuda familiar. Así, según el tiempo pasado juntos y del grado y el tipo de unión entre los miembros, pueden diferenciarse dentro de familie: 1) la kjernefamilie grupo que incluye a Ego y a su descendencia y a la pareja que reside con Ego, sea o no el padre o la madre reconocidos de la descendencia. De esta manera, generalmente, la kjernefamilie coincide con los miembros de la unidad doméstica. Pero no siempre ya que en el caso de las parejas homosexuales que tienen hijos biológicos con otra pareja homosexual, a pesar de que madre y padre no conviven, se incluyen en este grupo a los cuatro miembros de las dos parejas porque la no convivencia no es resultado de una ruptura sino del tipo de unión. Basándose en la consanguinidad y la afinidad cuando esta existe, este grupo se diferencia por ser el de las personas más próximas a Ego, con las que comparte residencia, intimidad y la vida diaria. 2) La familie consanguínea más próxima que incluye a padre y madre, herman@s, afines de l@s herman@s y a la descendencia de estos. Este grupo dentro de la familie responde a unos criterios especialmente de consanguinidad y se incorporan también las personas por afinidad y la relación existe y sigue siendo importante a pesar de que entre estos miembros no se vean muy a menudo. Pero esos lazos de "sangre" permiten a la persona estar segura de que la familie siempre estará pase lo que pase. 3) La familie por afinidad, es decir, la familie consanguínea de la pareja. Para que Ego incorpore como familie a este grupo es necesario un tiempo compartido, o un tiempo para la creación de una relación, de unos lazos que previamente no existían. Así, para algunos de mis informantes con relaciones de entre 2 y 4 años, la familie consanguínea de sus parejas no eran aún familie propia pero en cambio en aquellas relaciones de más larga duración este grupo de personas ya está incorporado, estableciéndose entre ellos ciertas obligaciones aunque no las mismas que con la familie consanguínea ya que la familie afín puede desaparecer con la separación de la pareja. Y 4) Dentro de la familie se hace otra diferenciación entre las personas que, por haber pasado más tiempo juntas han construido una relación más cohesionada que siguen manteniendo activa con la frecuencia de sus visitas. Así, por ejemplo, no formaran

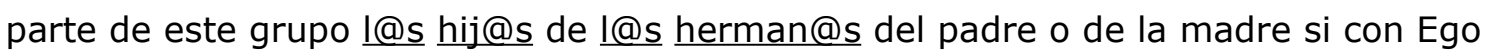
no han pasado suficiente tiempo juntos. En consecuencia, en este grupo se incluyen aquellas personas consideradas familie más cercana con la que se comparten el 


\section{perifèria}

Número 4, Julio 2006

www.periferia.name

tiempo libre y se realizan actividades de forma regular. A veces, Ego mantiene vigentes estas relaciones porque provienen de su niñez y por lo tanto están favorecidas por la relación que sus madre y/o padre ya mantenían y que le han transmitido, con lo cual, el tiempo y las experiencias compartidas son muchas desde la infancia, y otras veces por compatibilidad de caracteres y formas de ser.

A partir de estos cuatro grupos comunes para todos los informantes, cada uno de ellos continua las divisiones dentro de los miembros de la familie según las veces que tengan contacto con ellos y los contextos en los que se encuentran, índices del grado de relación existente $y$, por lo tanto, del tipo de deberes y obligaciones que tienen o qué pueden esperar de ellos.

3.- El resto de personas de las genealogías. No son identificados ni como slekt ni como familie sin embargo se representan en los árboles en la medida en que hay un vínculo de consanguinidad o afinidad reconocido por Ego pero no suficientemente estrecho -por no haber pasado tiempo juntos- como para relacionarse de forma directa. De esta manera, queda claro que no todas las relaciones de "sangre" son importantes aunque estas estén en la base del parentesco noruego.

Muchos de los informantes incluyen en sus árboles genealógicos otro grupo de personas: la vennskapsfamilie. La traducción del término sería "familia de amigos" y por lo tanto no están unidos al árbol con líneas de consanguinidad ni afinidad pero, de forma separada, ocupan un lugar importante para Ego. Este grupo está formado por amigos de Ego que este considera "como si fueran familia" porque la relación es mucho más estrecha que con alguien de la familie, incluso de la consanguínea. La frecuencia de las visitas entre este grupo puede ser diario y entre ellos comparten actividades que van más allá del ocio ya que, en el caso en el que hay hij@s, es normal que se espere de estas personas que tengan cuidado de estos cuando padre y/o madre no puedan ocuparse. En este sentido, una de las formas de institucionalizar este tipo de relación es mediante la figura del fadder (regiliosa) o vege (civil), es decir hacer padrino o madrina de un hij@ al miembro más cercano de la vennskapsfamilie. De esta manera, se implica legalmente al amigo en cuestiones familiares con la finalidad de fortalecer la relación y hacerla más inquebrantable en tanto las relaciones de amistad pueden finalizar. 


\section{perifèria}

Número 4, Julio 2006

www.periferia.name

\section{Madres, padres e hij@s en Oslo}

La centralidad que $\underline{\text { I@S }}$ niñ@s tienen para la sociedad noruega se pone especialmente de relieve tanto en los discursos que las instituciones y la sociedad articulan en torno a todos los aspectos relacionados con ellos -educación, sanidad, cuidado, etc.-, como en la práctica en la que, desde las ayudas y las políticas sociales hasta la organización de la cotidianidad, tienen como objetivo su bienestar. En mi opinión, la importancia de l@s niñ@s en Noruega reside en que son un elemento de cohesión social y familiar a la vez que son los receptores activos de la transmisión de la importante identidad nacional por parte de Estado, familia y sociedad. Pero, esta importancia tiene que hacerse compatible con las nociones de igualdad e individualismo tan importantes para los adultos, sobre todo para los

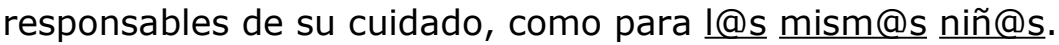

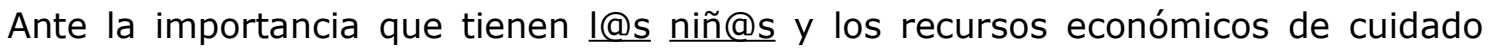
existentes así como las opciones de organización doméstica, en Noruega no se entiende que mujeres y hombres decidan por voluntad propia no tener hij@s. El contexto social e institucional no solo es favorable sino que además la presión social y el rechazo a esta opción son tan fuertes que las personas que toman esta decisión llegan a estar mal vistas socialmente e, incluso, tachadas de egoístas a la vez que acostumbran a distanciarse de la familia de origen. Este distanciamiento debe entenderse en la medida en que @@s niñ@s representan el punto de unión entre abuelos y padres en un contexto, el noruego, en que l@s hij@s dejan la casa familiar como muy tarde a los 19 años. La emancipación representa un distanciamiento entre padres e hij@s físico y en cierta forma también emocional ya que los jóvenes dejaran de buscar en la familia de origen sus referentes para encontrarlos en el grupo de pares. Es cuando esos hij@s se convierten en padres cuando la familia de origen, entendida como los padres y madres, se vuelven a acercar no a sus propi@s hij@s sino a sus niet@s. Así, $\underline{\text { @ }}$ niñ@s se convierten en el punto de unión entre los miembros de la familie consanguínea y afín (cuando esta existe) que reemprende la regularidad de sus visitas y aumenta el tiempo que pasan juntos, pero a la vez, también son el vínculo que confiere unión social a padres y madres. 


\section{perifèria}

Número 4, Julio 2006

www.periferia.name

Cuando los jóvenes noruegos se emancipan fortalecen hasta hacerlas principales, las relaciones que habían iniciado con sus grupos de pares. Así, la emancipación supone que esas relaciones entre amigos pasan a ser las más importantes: se busca en ellas el soporte, la ayuda y la reciprocidad. Una de las formas para mantener la cohesión de las relaciones con el grupo de pares es que, sus componentes acostumbran a seguir el mismo ritmo, en este caso, en el ciclo de emparejamiento y/o reproducción. Es normal, pues, que cuando en el seno del grupo de pares se empiece con el emparejamiento, todos sus miembros se emparejen más o menos al mismo tiempo y lo mismo pasa con convertirse en padre o madre. El principio que opera en la cohesión con el grupo de pares es el mismo para padres y abuelos: es decir, en el seno de las relaciones cotidianas más importantes con los pares, estar en las mismas condiciones o situación personal favorece que se tengan elementos en común $y$, por lo tanto, experiencias que compartir. En este sentido, hij@s o niet@s se convierten en elemento de cohesión de padres y abuelos con sus grupos de pares respectivos y no tenerlos supone un alejamiento del grupo y hasta cierta marginación no solo en las conversaciones sino en las actividades que el grupo realiza. En los casos en los que no existen niñ@s los adultos tienden también a buscar un grupo de pares que se encuentren en la misma situación.

La importancia de ser madre y padre debe congeniarse con las nociones culturales básicas de individualismo e igualdad. La representación de la maternidad y la paternidad en Oslo se basa más en un ejercicio, un rol, que en una identidad: la identidad que confiere el individualismo es la principal y es a partir de la cual se puede ser madre o padre pero también tener un rol en el lugar de trabajo o en el grupo de amigos. La incidencia del individualismo no solo está presente entre padre y madre sino que los hij@s también son individuos y es por está razón que la ideología educativa en Noruega ensalza la importancia de que la intervención de los adultos en las actividades de los niñ@s sea la mínima justamente para potenciar la creación de la relación entre pares y del desarrollo individual. En este sentido, las mujeres y los hombres madres y padres deben atender los múltiples ámbitos donde ejercen un rol y en el que mantienen una relación: consigo mismos, con la kjernefamilie, con el grupo de pares, con la familie, con el slekt y con el resto de 


\section{perifèria}

Número 4, Julio 2006

www.periferia.name

relaciones sociales y es con este propósito que entran en juego las nociones de tiempo e igualdad.

La clave está en cómo se organiza el tiempo con la intención de conseguir un equilibrio entre todos los ámbitos que requieren una dedicación que variará en función de la importancia del ámbito o de las relaciones, como ya hemos visto. Así, el ejercicio de la maternidad y la paternidad ocupan un lugar importante en la cotidianidad pero no el único: se debe combinar con el ámbito laboral pero también con el individualismo. En este sentido la igualdad, en este caso, en la responsabilidad del cuidado de $\underline{\text { @ }}$ niñ@s se comparte entre padre y madre ${ }^{15}$ y cuando no es posible uno de ellos se buscan alternativas entre el grupo de pares, el grupo de nuevas relaciones creadas a partir de l@s hij@s, los recursos públicos o entre la familie más cercana. Por este motivo, es corriente en Oslo que durante la semana padre y madre atiendan sus relaciones sociales o con ellos mismos mientras el otro cuida de los niñ@s y luego, en cierta manera, haya un relevo. Las personas en Oslo no solo son padres o madres sino que, ante todo, son individuos con otros ámbitos de relaciones de manera que el tiempo adquiere importancia en las representaciones de la maternidad y la paternidad en tanto siendo los principales responsables del cuidado de l@s hij@s y siendo estos tan importantes en la sociedad, han de saber buscar la equidad en qué tiempo y cómo lo usan con sus hij@s.

El contexto político-económico facilita a madres y padres poder combinar su ejercicio parental con sus otros ámbitos de actuación. Así, en la medida en que I@s niñ@s requieren tiempo y dinero para su cuidado ${ }^{16}$, el Estado interviene para que padres y madres cubran buena parte de ambas necesidades. En este sentido, el cuidado de l@s niñ@s debe entenderse como una estrategia adaptativa a ese contexto en el cual se busca el apoyo al cuidado pero también los modelos no solo de maternidad y paternidad, rechazando los de la generación inmediatamente anterior, sino de cuál es la manera correcta de educar a l@s hij@s. De nuevo, la intervención institucional en asuntos privados adquiere gran relevancia en la medida en que la sociedad la recibe de forma positiva y entre iguales. Recordemos

15 Cabe señalar que esa igualdad puede ser más teórica que práctica y por este motivo el Estado potencia la participación y el reparto de responsabilidades de los padres.

${ }^{16}$ Ver al respecto el trabajo de A. Leira (1996). 


\section{perifèria}

Número 4, Julio 2006

www.periferia.name

que, es entre iguales de la misma generación que se establecen las redes de ayuda y soporte a la vez que el más estricto control social en la crianza. Las redes pueden establecerse por iniciativa personal pero también institucional -en este sentido, existen los barselgruppa organizados en los centros primarios de salud, que son grupos de madres en baja postparto que necesitan compartir las experiencias diarias con otras madres en la misma situación-.

El contexto legislativo de ayudas económicas y de recursos públicos pero también la posibilidad que ofrece el Estado de disponer de tiempo para desarrollar cada uno de los ámbitos de relaciones, inciden de manera significativa en la elección de mis informantes de Oslo en tener descendencia y especialmente cuánt@s hij@s van a tener. Además, la importancia de los niñ@s en Noruega como vínculo de cohesión familiar y social lleva a que en los últimos años las mujeres noruegas tiendan a tener tres hij@s en vez de dos como hacían antes: no solo es muestra de cierto éxito económico sino de que ellas son capaces de poder encontrar el equilibrio entre todos los ámbitos de su vida lo que las lleva a ser vistas públicamente como mujeres competentes. Al margen de la igualdad entre géneros, no se tiene la misma visión de los padres. Pero, como ya he anunciado, @@ niñ@s adquieren también importancia en Noruega por ser los destinatarios de la transmisión de la identidad colectiva noruega a la vez que garantes de su continuidad.

\section{Parentesco e identidad}

Hay dos puntos de inflexión en la historia de Noruega: el primero se dio tras la independencia de Suecia $(1905)^{17}$ lo que supuso la necesidad de construir un país nuevo al que le era esencial una identidad colectiva nacional y una tradición en la que fundamentar no solo esa identidad sino todo aquello que los iba a diferenciar de sus antiguos ocupadores. El segundo punto de inflexión, como ya hemos visto, se dio en 1945 tras la ocupación nazi de Noruega y la universalización de las políticas sociales.

Para encontrar el contexto de creación de la nación noruega, debemos remontarnos a la Europa de 1848 en la que diversas revoluciones nacionalistas se desencadenaron paralelamente. En este momento, Noruega era un país con muy

\footnotetext{
17 Noruega se independizó de Dinamarca en 1814 pero este hecho no tuvo tanta incidencia en la formación identitaria porque siguió bajo soberanía sueca.
} 


\section{perifèria}

Número 4, Julio 2006

www.periferia.name

poca población y con una economía pobre basada en la agricultura y en la pesca que estaba bajo soberanía sueca, aunque en la práctica Suecia le permitía su desarrollo propio. En este marco de revoluciones nacionalistas en Europa se iniciaron las tareas de definición de una identidad nacional y una cultura noruega que culminaron en 1905. A partir de ese momento fue necesario no solo la adquisición de unas instituciones oficiales propias sino también la búsqueda de aquello específico de Noruega con el objetivo de que sirviera de diferenciación ante los antiguos colonizadores, con los cuales se compartía cultura y lenguas parecidas. Se pretendía que los noruegos pudieran construir unos lazos como un solo pueblo ante una situación de falta de historia, de cultura o de política propia y encontraron en la naturaleza de Noruega aquello singular y que podía unir a esa población sin tradición y sin símbolos nacionales ${ }^{18}$. La naturaleza fue tomada como motivo de inspiración para literatos y artistas y fue a partir de este momento en el que se empezó a construir la nación noruega: basándose en una forma de ser y de hacer marcada por una relación positiva con la naturaleza. Se vincularon de esta manera a un entorno rural donde encontraron la base de esa identidad nacional que no tenían y diferenciándose de suecos y daneses que se proyectaban más hacia el entorno urbano de sus ciudades. Como T. Larsen señala (1991), los noruegos han trasladado esos valores rurales fundados en su relación con el entorno natural a las ciudades ${ }^{19}$ suplantando la falta de una cultura urbana. Se creó de esta manera no solo una identidad nacional colectiva sino que se buscaron las prácticas y los símbolos que la sustentaran entre los cuales fueron los campesinos de montaña los principales dadores de esa identidad noruega más auténtica por estar en contacto directo con la naturaleza idealizada -aunque Noruega siempre había sido un país abierto al mar con una tradición pesquera que bien podría haber sido la dadora identitaria-. De esta manera, hay que entender que tanto la nación como la identidad colectiva noruega fue un producto político y cultural.

La identidad nacional noruega tiene un papel fundamental en la vida diaria: banderas, paseos por el bosque, esquiar, o cualquier otro símbolo identitario, como los pasteles o de prácticas, como estar al aire libre son cotidianas. A mi entender, la

\footnotetext{
${ }^{18}$ Ver los artículos escritos por Thomas Hylland Eriksen citados en la bibliografía.

${ }^{19}$ De hecho, a las personas que viven en Oslo se las conoce como Bønder $i$ byen, es decir campesinos en la ciudad.
} 


\section{perifèria}

Número 4, Julio 2006

www.periferia.name

necesidad diaria de recordar la identidad noruega, encuentra en la familia y en el cuidado de I@s niñ@s una vía de transmisión que garantiza su continuidad en un futuro. Solo cabe tomar como ejemplo el 17 de Mayo, el día Nacional de Noruega (Nasjonaldag), en el que a diferencia del resto de países del mundo, Noruega en vez de mostrar públicamente, en una desfilada, el potencial armamentístico que posee, los protagonistas de ese desfile y de todo el día son niñ@s y adolescentes. De nuevo, se pone de relieve la importancia de I@s niñ@s para la sociedad noruega pero también cómo confluyen la transmisión y el refuerzo de la identidad nacional con el valor que tiene una fuerte identidad local entendida esta como el vínculo con el lugar de origen de la persona o de la familia -y en el que, generalmente se encuentran las granjas ( $g a ̊ r d)$ - y esta identificación se muestra públicamente a través de los bunad o trajes tradicionales, cuya transmisión, generalmente, se da por vía consanguínea.

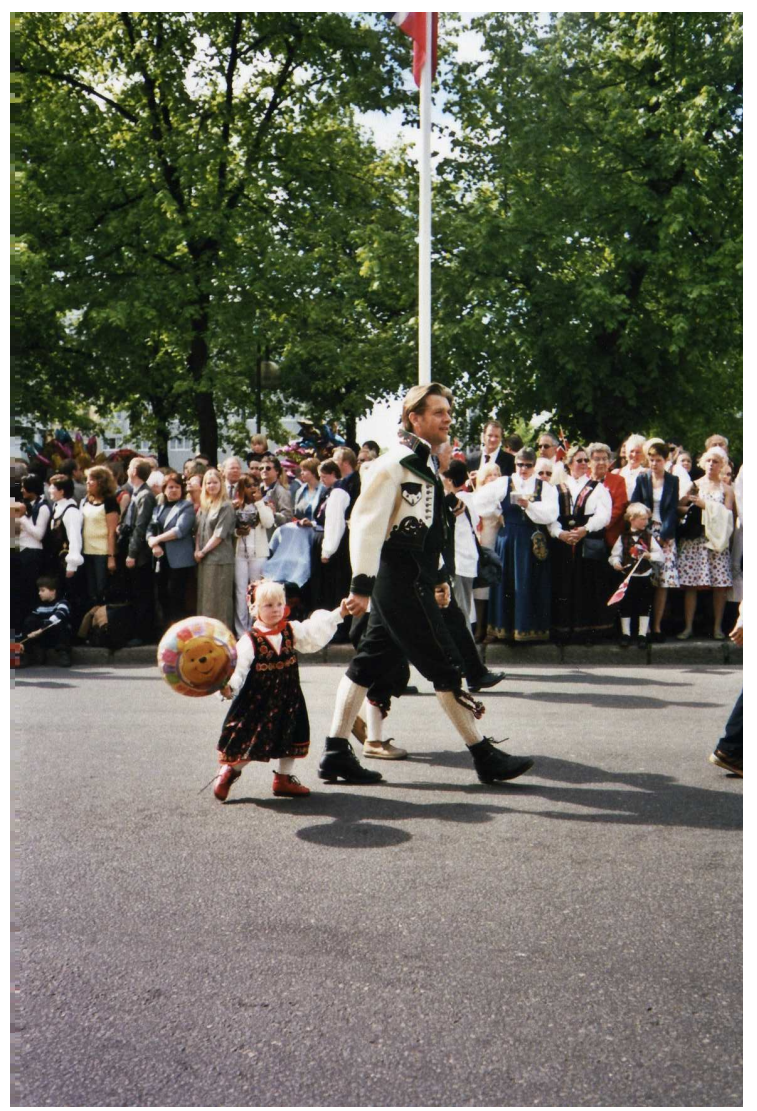

Oslo, 17 Mayo 2004.

Foto: Irina Casado i Aijón 


\section{perifèria}

Número 4, Julio 2006

www.periferia.name

Los bunad también fueron creados como símbolo identitario a finales del siglo XIX. Noruega está dividida en diversas regiones cada una de las cuales tiene un bunad específico y aquellas personas que sitúan su origen en una de estas zonas pueden llevar el bunad corresponfiente. Al estar vinculado el bunad con la zona de donde proviene la persona y/o la familia de origen, este traje se transmite entre generaciones relacionando así cada nueva generación con el lugar de donde proviene la familia, con el antepasado común. Es común privilegiar la transmisión del bunad y de la identidad local por vía materna pero bien es verdad que muchas veces puede ser el padre quien confiera esa identidad local o, incluso, que la misma persona escoja qué bunad quiere llevar. En estos últimos casos, se intenta establecer algún vínculo con la región de la cual se ha escogido el traje, bien sea por algún pariente lejano que proviniera de la zona o buscando alguna persona cercana que sirva de nexo de unión.

También existe acuerdo entre Estado y Sociedad para manifestar y reforzar la consciencia identitaria colectiva: lo importante es saberse noruegos y mostrarlo. Ante esto, se ha llevado a cabo una fuerte ritualización de aquellas prácticas identitarias que se realizan por el conjunto de la sociedad pero también en familia que, como ya he dicho, es una de las principales vías de transmisión a I@s niñ@s aunque no la única por la fuerte influencia de las escuelas, del Estado y del resto de la Sociedad en la vida privada-. En la medida en que las personas deben planear su tiempo y distribuirlo entre los ámbitos de relaciones, empezando por el propio individualismo, estas utilizan unos escenarios concretos para manifestar y hacer las actividades correspondientes a cada uno de esos ámbitos. $Y$ esos escenarios, con sus prácticas ritualizadas, están identificados dentro del contenido de la identidad colectiva noruega. Cada uno de los ámbitos de relaciones tiene unos escenarios donde activarse a la vez que está asociado a un tipo de prácticas generalmente llamadas typisk norsk. Así, las nociones culturales básicas, como el individualismo o el tiempo, pero también las personas y sus ámbitos de relaciones tienen en la identidad un marco de desarrollo en el que los escenarios, los símbolos y las prácticas están previstas.

Buena parte de los escenarios donde transcurre el tiempo para las relaciones están en el exterior: generalmente en los bosques pero también en las calles, parques y 


\section{perifèria}

Número 4, Julio 2006

www.periferia.name

plazas e, incluso, los cafés. Otra parte, aunque no la mayoritaria, tiene como escenario el interior de las casas. De este modo, en un contexto en el que, como hemos visto, el individualismo requiere una parte importante del tiempo, los miembros de la kjernefamilie encuentran en los escenarios y las actividades ritualizadas $^{20}$ el marco donde cohesionar su relación más allá de la intimidad cotidiana de sus hogares en la que no siempre coinciden. Es común, pues, que durante los fines de semana, padres, madres e hij@s salgan a la naturaleza -como escenario identitario por excelencia- a esquiar pero también a caminar, hacer hogueras y cocinar en ellas. Es así como cohesionan una relación que durante la semana apenas surge durante el tiempo de la comida principal pero también es así como se da la transmisión de la identidad noruega a I@s niñ@s.

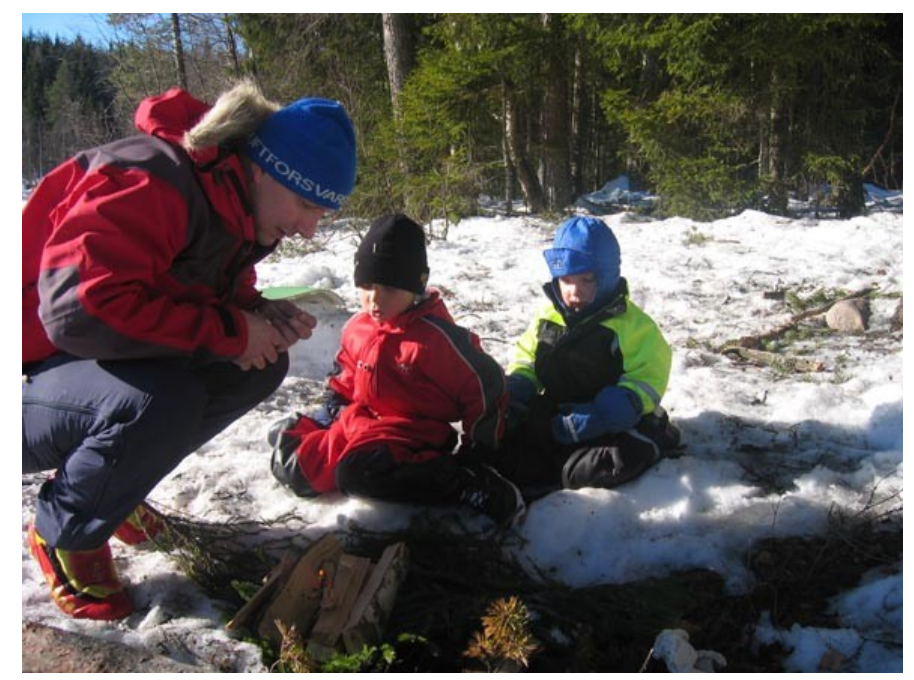

Padre e hijos haciendo una hoguera en el bosque.

Foto: Irina Casado i Aijón

La relación con la kjernefamilie, con la familie y con el slekt se manifiestan en prácticas ritualizadas en las que los símbolos nacionales están siempre presentes: es una forma de expresión. A la vez, esas relaciones entre miembros de la familie y del slekt están consideradas en si mismas por los informantes como específicamente noruegas. Es decir, incorporan al contenido de la identidad nacional el entramado de relaciones de parentesco, en tanto singulares de esta sociedad,

${ }^{20}$ Estas actividades familiares también son de interés institucional y con el objetivo de proponer las mejores actividades a las familias, el Estado edita unos libritos gratuitos. 


\section{perifèria}

Número 4, Julio 2006

www.periferia.name

estableciendo así un doble vínculo entre parentesco e identidad: por un lado, las relaciones de parentesco usan escenarios y prácticas ritualizadas para su desarrollo $y$, por el otro, la propia identidad utiliza el parentesco como otra forma de expresión. Una especificidad, la del parentesco noruego, que tiene como ejes centrales la diversidad de formas de unión y su regularización pero sobre todo la diversidad de núcleos procreativos existentes.

\section{A modo de reflexión final}

La sociedad noruega vive muy pendiente de manifestar diariamente su identidad nacional. El Estado tiene un papel determinante en esto pero, a la vez, también tiene una implicación fundamental y sistemática en la organización de la procreación: prácticamente cada día la prensa publica artículos referentes a aspectos del cuidado y educación de I@s niñ@s pero también sobre maternidad y paternidad proponiendo, de este modo, un modelo de lo que debiera ser. La sociedad opina acerca de esos modelos creando así unos debates sociales, un diálogo Sociedad-Estado en el que ambos pueden modificar posiciones. Los temas concernientes a la procreación están en el orden del día en Noruega: generan un interés que busca hacer en todo momento lo más correcto porqué los principales implicados son I@s niñ@s. Estado y Sociedad velan por su bienestar de la misma forma que mantienen muy activa la demostración pública de su identidad nacional de la cual también son no solo representantes sino también receptores.

Estado, Sociedad y contenido de la identidad nacional tienen como ejes vertebradores unas nociones culturales básicas en las que se fundamentan sus acciones y discursos pero, a la vez, generan un contexto en el que pueden seguir vigentes. Es así como, las pautas, los modelos y las prácticas en torno al cuidado de I@s niñ@s, a la maternidad y a la paternidad se representan y se organizan: tomando el contexto general en el que convergen nociones culturales y políticas estatales y diseñando estrategias adaptativas. En este sentido, y retomando parte de la argumentación inicial, si la procreación parece no ser una tarea individual, que necesita un soporte y una ayuda para llevarse a cabo, Noruega correspondería a un modelo, más que a un estadio evolutivo, en el que el Estado incidiría en conjunción con la lógica cultural subyacente mientras, podríamos esperar que en cualquier otra 


\section{perifèria}

Número 4, Julio 2006

www.periferia.name

sociedad esa dependencia o búsqueda de soporte lo cubrirían, por ejemplo, otras esferas quizá más próximas al individuo, quizá en combinación entre varias.

Así, mientras en Noruega es importante identificar cuál es el símbolo que más especificidad cultural les proporciona o la dialéctica Sociedad-Estado se focaliza en la idea de necesidad-ayuda, los noruegos transcurren su tiempo en unos escenarios en los que se pretende el encuentro del equilibrio.

\section{Bibliografía}

Archetti, E. (1991). "De I'Ideologie du Pouvoir. Analyse culturelle comparative" en Klausen, A.M. Le Savoir-être norvegien. Regards anthropologiques sur la culture norvégienne. Paris: L'Harmattan. Pp. 243-261.

Blom, I. (1996[1991]). "Maternidad voluntaria, 1900-1930: teoría y política de una feminista noruega desde una perspectiva internacional" en Bock, G. y Thane, P (eds.). Maternidad y políticas de género. La mujer en los estados de bienestar europeos, 1880-1950. Madrid: Ediciones Cátedra. Pp.51-80.

Casado i Aijón, I. "Ser dona, ser home. Natura i cultura en la construcció de les identitats de gènere a Oslo i Sabadell" a Butlletí del Club Escandinau. Centre Cultural Nòrdic, núm. 1 (gener-abril, 2004). Pp. 16-17.

González Echevarría, A. (1995). "Hacia una Antropología de la Procreación" en Familia y Sociedad, núm. 3. Pp. 95-110.

González Echevarría, A. (Diciembre 2005). "Informe sobre el estado del desarrollo de la Antropología de la Procreación" en Perifèria, núm. 3 http://antalya.uab.es/antropologia/periferia/catala/numero3/periferia_3 $0 . p d f$ Gullestad, M. (1992). The Art of Social Relations. Essays on Culture, Social Action and Everyday Life in Modern Norway. Oslo: Scandinavian University Press.

Hernes, H.M. (1987). Welfare State and Woman Power. Essays in State Feminism. Oslo: Norwegian University Press.

Hylland Eriksen, Th. "Los noruegos y la naturaleza". Oslo: Utenriksdepartementet. http://odin.dep.no/odinarkiv/norsk/ud/2000/p10001967/032001-990125/dokbn.html 


\section{perifèria}

Número 4, Julio 2006

www.periferia.name

Hylland Eriksen, Th. "Globalización e identidad noruega". Oslo: Utenriksdepartementet.

http://odin.dep.no/odin/spansk/p10001917/p10001926/032001-990159/dok-

bu.html

Hylland Eriksen, Th. (1997). "The nation as a human being - a metaphor in a midlife crisis? Notes on the imminent collapse of Norwegian national identity" en http://folk.uio.no/geirthe/Collapse.html

Larsen, T. (1991). "Des paysans en ville. À la recherché d'une identité norvégienne" en Klausen, A.M. Le Savoir-être norvegien. Regards anthropologiques sur la culture norvégienne. Paris: L'Harmattan. Pp. 33-75.

Leira, A. (1996). Parents, Children and the State: Family obligations in Norway. Oslo: Institutt for Samfunnsforskning.

Seip, A-L. y Ibsen, H. (1996[1991]). "Prestaciones familiares, ¿qué política? El camino hacia el subsidio familiar en Noruega" en Bock, G. y Thane, P (eds.). Maternidad y políticas de género. La mujer en los estados de bienestar europeos, 1880-1950. Madrid: Ediciones Cátedra. Pp. 81-113. 